\title{
Frontal plane knee alignment among normal northern Nigerian adults: A radiographic study
}

\author{
Abdullahi Suleiman Gwani, ${ }^{1}$ Eduitem Sunday Otong, ${ }^{1}$ Sani Abubakar Bello, ${ }^{1}$ \\ Hamza Mustapha Ahmed, ${ }^{2}$ Dlama Zira Joseph, ${ }^{2}$ Yusuf Aliyu ${ }^{2}$ \\ ${ }^{1}$ Department of Human Anatomy, Faculty of Basic Medical Sciences, College of Medical Sciences, \\ Abubakar Tafawa Balewa University, Bauchi; ${ }^{2}$ Department of Radiology, Abubakar Tafawa Balewa \\ University Teaching Hospital, Bauchi, Bauchi State, Nigeria
}

\begin{abstract}
Studies have shown that knee alignment parameters differ among races. However, to our knowledge, radiographic frontal plane knee alignment has not been studied in normal northern Nigerian adults. The objective of this study was therefore to determine the frontal plane knee alignment in normal northern Nigerian adults. This study recruited a total of 59 consented subjects (44 males, 15 females). The entire subjects are without any history of lower extremity deformity. Anteroposterior radiographs of both knees with the patella positioned straight ahead were obtained from each participant while standing in a relaxed bipedal stance and placing equal weight on each limb. Alignment was assessed by measuring the tibiofemoral angle (TFA), distal femoral angle (DFA) and proximal tibial angle (PTA). The angles were measured with the aid of a universal plastic goniometre and a plastic ruler. Descriptive statistics of the alignment parameters, independent and paired t-test were computed. In the male population, the mean (standard deviation) obtained were $179.06(3.87)^{\circ}$ for the TFA, 85.94 (3.03 ${ }^{\circ}$ for the DFA and $89.27(3.26)^{\circ}$ for the PTA. In the female population, the values were $179.53(3.38)^{\circ}$ for the TFA, $86.40(2.97)^{\circ}$ for the DFA and
\end{abstract}

\footnotetext{
Correspondence: Abdullahi Suleiman Gwani, Department of Human Anatomy, Faculty of Basic Medical Sciences, College of Medical Sciences, Abubakar Tafawa Balewa University, PMB 0248, Bauchi, Bauchi State, Nigeria.

Tel.: +234.8139796989.

E-mail: asgwani@yahoo.com

Key words: knee, varus, valgus, alignment, deformity.

Contributions: the authors contributed equally.

Conflict of interest: the authors declare no potential conflict of interest.

Funding: none.

Received for publication: 25 November 2018.

Accepted for publication: 30 November 2019.

This work is licensed under a Creative Commons Attribution NonCommercial 4.0 License (CC BY-NC 4.0).

${ }^{\circ}$ Copyright: the Author(s), 2019

Licensee PAGEPress, Italy

Annals of African Medical Research 2019; 2:59

doi:10.4081/aamr.2019.59
}

$89.27(2.15)^{\circ}$ for the PTA. No significant mean difference was observed between genders in all the parameters. The TFA does not show any significant difference between the right and left angle regardless of gender. However, significant mean differences were observed in the DFA and PTA of males and combined population. No significant difference was observed in the DFA and PTA of females. Accordingly, northern Nigerian adults may have varus knee alignment compared to other races. Thus, this pre-existing varus alignment should be taken into consideration during clinical examination, preoperative planning and postoperative evaluations of knee deformities in this population.

\section{Introduction}

The knee joint is the largest, most superficial, one of the most complex, and the most stressed joint in the human body. ${ }^{1,2}$ It is primarily a hinge type of synovial joint that is made up of three main bones: the femur, tibia, and patella, which form two distinctly separate articulations - the tibiofemoral joint between the two femoral condyles and two tibial plateaus, and the patellofemoral joint between the trochlea surface of the femur and the patella.

The femur and the tibia are specially configured so that the load-bearing axis of the lower extremity passes through the centre of the knee. The femoral neck overhangs the shaft so that the former is placed diagonally within the thigh; whereas the tibia is vertically placed within the leg. Thus, when standing, the knees are adjacent and placed directly inferior to the trunk, returning the centre of gravity to the vertical lines of the supporting legs and feet. ${ }^{2}$ Sequel to this configuration, the anatomic axes of the femur and tibia do not coincide. This creates an obtuse angle at the knee referred to as the tibiofemoral angle, which is vital in evaluating frontal plane knee alignment. The geometry of the distal femur and proximal tibia is also closely associated with the biomechanics of the tibiofemoral and patellofemoral joints. ${ }^{3}$ Thus, the orientation of the femoral condyles and the tibial plateaus relative to the long axis of their respective bones is also an important consideration when assessing knee alignment. The orientation of the femoral condyle relative to the femoral axis is referred to as distal femoral angle while that of tibial plateau relative to the tibial axis is referred to as the proximal tibial angle.

Knee malalignment has been identified as a risk factor for both development and progression of knee osteoarthritis. The malalignment can take the form of varus angulation, where the distal segment of the extremity shifts toward the midline, or valgus angulation, in which the distal segment of the limb shifts away from the midline. ${ }^{4}$ Varus knee malalignment is associated with the risk of development of knee osteoarthritis whereas; both varus and valgus knees are asso- 
ciated with greater risk of progression of pre-existing medial and lateral compartment knee osteoarthritis respectively. ${ }^{5-7}$ During gait, the distribution of load is not equal between the medial and lateral knee compartments: $70 \%$ of load passes through the medial compartment, mainly because of an external knee adduction moment. In a varus knee, however, the axis passes medial to knee centre, creating a moment arm which increases force across the medial compartment. Thus, the proportion of load distributed medially increases further with an increase in varus knee. In a valgus knee, on the other hand, the axis passes lateral to knee centre, and the resulting moment arm increases force across the lateral compartment. With greater valgus, the load distribution shifts from greater medial, to equal, or even to greater lateral with more severe valgus. ${ }^{8}$

It has been reported that the prevalence of knee osteoarthritis as well as other musculoskeletal disorders differ among races. ${ }^{9,10}$ Consequently, more attention has been given to racial differences in lower extremity alignment particularly with the advent of newer designs of total knee arthroplasty prostheses. ${ }^{11-15}$ Indeed, researchers have realised and reported differences in alignment parameters among races. Hence, the need for establishing a standard value for each population has been stressed. ${ }^{16}$ However, to our search, radiographic frontal plane knee alignment has not been studied in normal northern Nigerian adults. Thus, the objective of this study was to determine the normal values of frontal plane knee alignment parameters in this population.

\section{Materials and Methods}

\section{Participants}

The participants for this study were randomly recruited from the patient population attending Radiology Department of the Abubakar Tafawa Balewa University Teaching Hospital (ATBUTH), Bauchi, Nigeria. Their consent was sought as they attend the Hospital for various radiological procedures other than

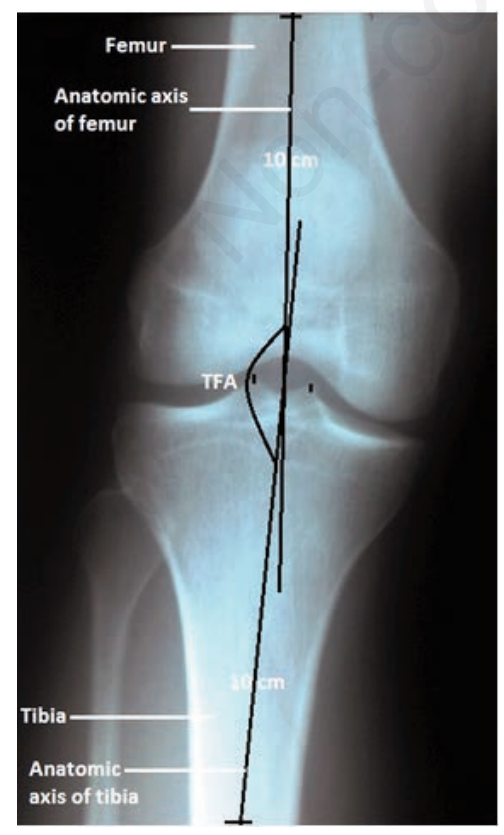

Figure 1. Procedure for measurement of tibiofemoral angle. those related to the lower extremity. In addition, the participants did not have any history of lower extremity deformity, lumbosacral pathology, neurological disorder or any systemic disease affecting the lower extremity. A total of 59 subjects (44 males, 15 females) were recruited. The study was approved by the Human Ethics committee of the ATBUTH.

\section{Procedure}

Anteroposterior radiographs of both knees were obtained from each participant. The participants stood in a relaxed bipedal stance, placing equal weight on each limb. To position the patella straight ahead, the participants were instructed to place their feet beside two straight lines drawn $15 \mathrm{~cm}$ apart. The radiographic film cassette was placed behind the knees at a distance of $100 \mathrm{~cm}$ from the $\mathrm{X}$-ray tube. The X-ray beam was directed horizontally and centered at the knee joints. The same exposure of $13 \mathrm{mAs}$ at $70 \mathrm{KV}$ was maintained for all radiographs. All the radiographs were taken by the same radiographer.

\section{Measurements}

The alignment was measured according to the method described by Kraus et al. ${ }^{17}$ The measurements were made directly on X-ray film viewer with the aid of a sharp clutch pencil, plastic ruler, and a universal plastic goniometre. The midpoint between the two tips of tibial spines was used as the centre of the knee joint. With the aid of a pencil, marks were made on the tip of the tibial spines. Then, a ruler was used to locate the exact distance between the tips, as well as the midpoint of the tips, of the two spines. The anatomic axis of femur was defined as the line connecting the midpoint of the tip of the tibial spines to a point $10 \mathrm{~cm}$ on the centre of the distal femoral shaft, while the anatomic axis of the tibia was defined as the line connecting the midpoint of the tip of the tibial spines to a point $10 \mathrm{~cm}$ on the centre of the proximal tibial shaft. Tibiofemoral angle (Figure 1) was measured as the lateral angle formed by the anatomic axes of the femur and tibia. Distal femoral angle (Figure 2) was formed laterally by the anatomic axis of the

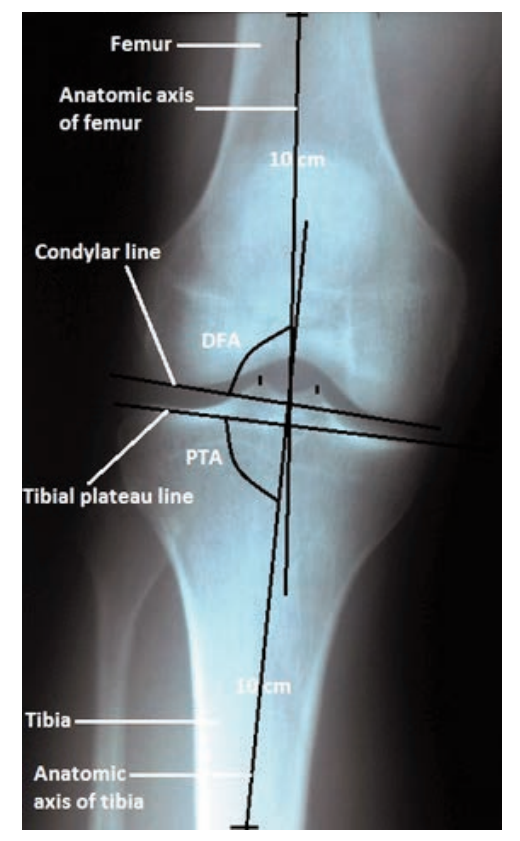

Figure 2. Procedure for measurement of distal femoral angle and proximal tibial angle. 
femur and a line tangential to the most distal points on the convexity of the two femoral condyles (condylar line). Proximal tibial angle (Figure 2) was also formed laterally by the anatomic axis of the tibia and a line across the flat or concave aspect of the subchondral line of the two tibial plateaus (tibial plateau line).

\section{Statistical analysis}

Statistical analyses were performed using IBM SPSS Statistics (version 22) software, Armonk, New York. Kolmogorov-Smirnov test was used to check whether the data were normally distributed before conducting further analysis. The level of significance in all statistical analyses was set at $\mathrm{P}<0.05$. The descriptive statistics of the parameters are expressed as mean (SD), 95\% CI, including minimum and maximum values. An independent t-test was used to compare the mean differences in the alignment parameters between males and females. Paired t-test was used to check for differences in these parameters between the right and left knees.

\section{Results}

The demographic data were analyzed. The overall mean (SD) age of the participants (male and female) was 24.49 (5.42) (range 18-35) years, height 167.76 (7.39) (range 148-186) $\mathrm{cm}$ and weight 57.72 (9.01) (range 40-82) kg. The detailed demographic data for male and female participants is presented in Table 1.

The descriptive statistics of the alignment parameters is presented in Table 2. The results of independent t-test (Table 3) showed no significant difference in the alignment parameters between genders ( $\mathrm{P}>0.05$ and $95 \% \mathrm{CI}$ crosses 0 in all the parameters). The result of paired sample t-test (Table 4) does not show any significant difference in TFA between the right and left angle regardless of gender. However, a significant difference was observed in the DFA of males and combined population, as well as the PTA of males and the combined population. No significant difference was observed in the DFA and PTA of females.

Table 1. Demographic characteristics of the participants $(n=59)$.

\begin{tabular}{|c|c|c|c|c|c|}
\hline Gender & Characteristics & Mean (SD) & $95 \% \mathrm{CI}$ & Min & Max \\
\hline Male $(n=44)$ & $\begin{array}{l}\text { Age (years) } \\
\text { Height }(\mathrm{cm}) \\
\text { Weight }(\mathrm{kg})\end{array}$ & $\begin{array}{c}24.18(5.09) \\
169.84(5.68) \\
58.88(9.38)\end{array}$ & $\begin{array}{c}22.63,25.72 \\
168.11,171.56 \\
56.03,61.74\end{array}$ & $\begin{array}{c}18.00 \\
159.00 \\
44.00\end{array}$ & $\begin{array}{c}35.00 \\
186.00 \\
82.00\end{array}$ \\
\hline Female $(\mathrm{n}=15)$ & $\begin{array}{l}\text { Age (years) } \\
\text { Height }(\mathrm{cm}) \\
\text { Weight }(\mathrm{kg})\end{array}$ & $\begin{array}{c}25.40(6.40) \\
161.66(8.60) \\
54.33(7.01)\end{array}$ & $\begin{array}{c}21.85,28.94 \\
156.90,166.43 \\
50.44,58.21\end{array}$ & $\begin{array}{c}18.00 \\
148.00 \\
40.00\end{array}$ & $\begin{array}{c}35.00 \\
178.00 \\
68.00\end{array}$ \\
\hline Combined $(\mathrm{n}=59)$ & $\begin{array}{l}\text { Age (years) } \\
\text { Height }(\mathrm{cm}) \\
\text { Weight }(\mathrm{kg})\end{array}$ & $\begin{array}{l}24.49(5.42) \\
167.76(7.39) \\
57.72(9.01)\end{array}$ & $\begin{array}{c}23.07,25.90 \\
165.83,169.68 \\
55.38,60.07\end{array}$ & $\begin{array}{c}18.00 \\
148.00 \\
40.00\end{array}$ & $\begin{array}{l}35.00 \\
186.00 \\
82.00\end{array}$ \\
\hline
\end{tabular}

$\mathrm{SD}=$ standard deviation, $\mathrm{CI}=$ confidence interval, $\mathrm{n}=$ number of subjects, min. $=$ minimum, max. $=$ maximum.

Table 2. Descriptive statistics of the alignment parameters.

\begin{tabular}{|c|c|c|c|c|c|c|}
\hline Side & Gender & Variable & Mean (SD) & $95 \%$ CI & Min. & Max. \\
\hline Right & $\begin{array}{c}\text { Male } \\
\text { Female } \\
\text { Combined }\end{array}$ & $\begin{array}{l}\text { TFA } \\
\text { DFA } \\
\text { PTA } \\
\text { TFA } \\
\text { DFA } \\
\text { PTA } \\
\text { TFA } \\
\text { DFA } \\
\text { PTA }\end{array}$ & $\begin{array}{c}178.82(3.87) \\
86.36(2.80) \\
88.61(3.01) \\
179.53(3.14) \\
86.40(2.87) \\
88.87(1.88) \\
179.00(3.69) \\
86.37(2.80) \\
88.68(2.75)\end{array}$ & $\begin{array}{c}177.64,179.10 \\
85.51,87.22 \\
87.70,89.52 \\
177.80,181.27 \\
84.81,87.99 \\
87.82,89.91 \\
178.04,179.96 \\
85.64,87.10 \\
87.96,89.39\end{array}$ & $\begin{array}{c}173.00 \\
80.00 \\
81.00 \\
177.00 \\
83.00 \\
85.00 \\
173.00 \\
80.00 \\
81.00\end{array}$ & $\begin{array}{c}189.00 \\
96.00 \\
94.00 \\
187.00 \\
92.00 \\
91.00 \\
189.00 \\
96.00 \\
94.00\end{array}$ \\
\hline Left & $\begin{array}{c}\text { Male } \\
\text { Female } \\
\text { Combined }\end{array}$ & $\begin{array}{l}\text { TFA } \\
\text { DFA } \\
\text { PTA } \\
\text { TFA } \\
\text { DFA } \\
\text { PTA } \\
\text { TFA } \\
\text { DFA } \\
\text { PTA }\end{array}$ & $\begin{array}{c}179.30(3.89) \\
85.52(3.22) \\
89.93(3.40) \\
179.53(3.72) \\
86.40(3.16) \\
89.67(2.38) \\
179.36(3.82) \\
85.75(3.20) \\
89.86(3.15)\end{array}$ & $\begin{array}{c}178.11,180.48 \\
84.54,86.50 \\
88.90,90.97 \\
177.47,181.59 \\
84.65,88.15 \\
88.35,90.98 \\
178.36,180.35 \\
84.91,86.58 \\
89.04,90.69\end{array}$ & $\begin{array}{c}172.00 \\
73.00 \\
76.00 \\
174.00 \\
82.00 \\
85.00 \\
172.00 \\
73.00 \\
76.00\end{array}$ & $\begin{array}{c}189.00 \\
92.00 \\
96.00 \\
188.00 \\
93.00 \\
93.00 \\
189.00 \\
93.00 \\
96.00\end{array}$ \\
\hline Combined & Female & $\begin{array}{l}\text { TFA } \\
\text { DFA } \\
\text { PTA } \\
\text { TFA } \\
\text { DFA } \\
\text { PTA } \\
\text { TFA } \\
\text { DFA } \\
\text { PTA }\end{array}$ & $\begin{array}{c}179.06(3.87) \\
85.94(3.03) \\
89.27(3.26) \\
179.53(3.38) \\
86.40(2.97) \\
89.27(2.15) \\
179.18(3.74) \\
86.06(3.01) \\
89.27(3.01)\end{array}$ & $\begin{array}{c}178.24,179.88 \\
85.30,86.59 \\
88.58,89.96 \\
178.27,180.80 \\
85.29,87.51 \\
88.46,90.07 \\
178.50,179.86 \\
85.51,86.61 \\
88.72,89.82 \\
\end{array}$ & $\begin{array}{c}172.00 \\
73.00 \\
76.00 \\
174.00 \\
82.00 \\
85.00 \\
172.00 \\
73.00 \\
76.00 \\
\end{array}$ & $\begin{array}{c}189.00 \\
96.00 \\
96.00 \\
188.00 \\
93.00 \\
93.00 \\
189.00 \\
96.00 \\
96.00 \\
\end{array}$ \\
\hline
\end{tabular}

TFA = tibiofemoral angle, $\mathrm{DFA}=$ distal femoral angle, $\mathrm{PTA}=$ proximal tibial angle, $\mathrm{SD}=$ standard deviation, $\mathrm{CI}=$ confidence interval, min. $=$ minimum, max. $=$ maximum 


\section{Discussion}

Alignment of the knee and the orientation of the tibiofemoral joint are essential components of accurate clinical examination, preoperative planning, and postoperative evaluations - whether considering fracture reduction, total knee arthroplasty, or deformity correction. Undeniably, the success of both surgical and conservative management of knee deformities depends mainly on the restoration of normal alignment and normal joint orientation. ${ }^{18}$ If knee replacement, for example, leaves the extremity in malalignment, loosening and instability occur at a greater rate than if the limb is well aligned. ${ }^{19}$ Indeed, malalignment of greater than $5^{\circ}$ in either varus or valgus direction has been shown to be associated with more functional decline compared to knees with less malalignment. ${ }^{7}$ Thus, knowledge of the normal range of values of knee alignment parameters for a given population is crucial in order to make an accurate diagnosis and effectively manage knee deformities in that population.

The mean value of the TFA obtained in the current study showed the presence of varus knee alignment in northern Nigerian adults. Earlier studies in American ${ }^{20}$ and Chinese ${ }^{14}$ populations have also reported varus alignment in both men and women. Similarly, Matsumoto et al. ${ }^{21}$ also reported slight varus alignment among Japanese subjects. Additionally, Song et al..$^{22}$ also reported constitutional varus knee alignment among Korean females. On the other hand, the mean TFA in the present study is larger than the values reported in other Africans ${ }^{23,24}$ and Saudi $^{25}$ populations. Variation in femoral length, in addition to genetic, dietary and environmental factors has been implicated for these differences. ${ }^{16}$ Regarding sexual dimorphism in the TFA, the present study found no significant difference in both the right and left angles between genders. Similar findings have also been reported in Malawians, ${ }^{23}$ Chinese, ${ }^{26}$ Saudis $^{25}$ and American Caucasians. ${ }^{27}$ On the contrary, Khattak et al. $^{28}$ reported more varus alignment in men than women. Similarly, a study comparing the clinical measurement of TFA among Japanese and Australian population reported that female subjects had a significantly smaller angle (less varus) than the males. ${ }^{13}$ The current study also found that the right and left angles do not significantly differ regardless of gender. However, this is contrary to the findings in adult Saudis in which, the left angle was significantly larger in males and in the combined population. $^{25}$

A decrease in the lateral-to-medial slope of the distal femur creates a larger DFA, which indicate an increasing varus orientation of the distal femur. ${ }^{29}$ Surveys of limb alignment have shown that abnormal femoral geometry, in which the lateral-to-medial slope of the distal femur is averagely less than normal, is the most common cause of varus malalignment in osteoarthritic patients. ${ }^{30}$ Indeed, the greater prevalence of valgus (knock-knee) alignment in females than males was attributed largely to femoral geometry. ${ }^{31}$ The mean distal femoral angle found in the present study is lower than that of Malawian and Saudi population, but larger than the findings in Indian population. ${ }^{32}$ No significant gender difference was observed regarding the angle in the current study. On the other hand, the right DFA is significantly larger in males $(\mathrm{P}=0.014)$ and in the combined population ( $\mathrm{P}=0.047)$ whereas in females no significant difference was observed. However, this is not the case with Saudi population in which no significant difference with respect to gender and side of the body. ${ }^{25}$ A study among Malawian population also shows no significant difference in terms of gender. ${ }^{16}$

Unlike the DFA, the PTA does not greatly influence knee alignment. Indeed, Derek et al. ${ }^{30}$ found that the tibial plateau slope (measured by the PTA) was essentially the same in normal and osteoarthritic groups. In the present study, the PTA was similar to the findings in Malawian and Saudi populations. Similarly, no significant gender difference was observed in the present study. However, the left angle was significantly larger in males $(\mathrm{P}=0.021)$ and in the combined population $(\mathrm{P}=0.008)$, while in females no significant difference was noted. Nevertheless, in Saudi, no significant difference was observed with respect to gender and side of the body. ${ }^{25}$ Similarly, a study among Malawian population also showed no significant difference in term of gender. ${ }^{16}$ However, contrary to these findings, Khattak et al. ${ }^{28}$ reported that the mean PTA was more medially inclined in Pakistani men than women.

Table 3. Result of independent t-test for the variables between males and females.

\begin{tabular}{lccc} 
Variables $\left(^{\circ}\right)$ & $\begin{array}{c}\text { Mean diff. } \\
(95 \% \mathrm{CI})\end{array}$ & $\begin{array}{c}\text { t-statistics } \\
(\mathrm{df})\end{array}$ & $\begin{array}{c}\text { P-values } \\
\text { RTFA }\end{array}$ \\
LTFA & $-0.72(-2.93,1.50)$ & $-0.65(57)$ & 0.521 \\
RDFA & $-0.24(-2.54,2.07)$ & $-0.21(57)$ & 0.837 \\
LDFA & $-0.04(1.73,1.65)$ & $-0.04(57)$ & 0.966 \\
RPTA & $-0.25(-1.91,1.41)$ & $-0.92(57)$ & 0.363 \\
LPTA & $0.27(-1.64,2.17)$ & $0.28(57)$ & 0.761 \\
\hline
\end{tabular}

TFA = tibiofemoral angle, $\mathrm{DFA}=$ distal femoral angle, $\mathrm{PTA}=$ proximal tibial angle, $\mathrm{CI}=$ confidence interval.

Table 4. Results of paired sample t-test between the right and left angles in males, females and combined sample.

\begin{tabular}{|c|c|c|c|c|c|}
\hline Variables (0) & Gender & Mean diff. (SD) & $95 \%$ CI & t-statistics (df) & P-values \\
\hline TFA & $\begin{array}{c}\text { Male } \\
\text { Female } \\
\text { Combined }\end{array}$ & $\begin{array}{c}-0.48(3.97) \\
0.00(2.59) \\
-0.36(3.65)\end{array}$ & $\begin{array}{l}-1.68,0.73 \\
-1.43,1.43 \\
-1.31,0.60\end{array}$ & $\begin{array}{c}-0.80(43) \\
0.00(14) \\
-0.75(58)\end{array}$ & $\begin{array}{l}0.429 \\
1.000 \\
0.457\end{array}$ \\
\hline DFA & $\begin{array}{c}\text { Male } \\
\text { Female } \\
\text { Combined }\end{array}$ & $\begin{array}{l}0.84(2.17) \\
0.00(2.88) \\
0.63(2.37)\end{array}$ & $\begin{array}{c}0.18,1.50 \\
-1.59,1.59 \\
0.01,1.24\end{array}$ & $\begin{array}{l}2.57(43) \\
0.00(14) \\
2.03(58)\end{array}$ & $\begin{array}{c}0.014^{*} \\
1.000 \\
0.047^{*}\end{array}$ \\
\hline PTA & $\begin{array}{c}\text { Male } \\
\text { Female } \\
\text { Combined }\end{array}$ & $\begin{array}{l}-1.32(3.65) \\
-0.80(2.11) \\
-1.19(3.32)\end{array}$ & $\begin{array}{l}-2.43,-0.21 \\
-1.97,0.37 \\
-2.05,-0.32\end{array}$ & $\begin{array}{l}-2.39(43) \\
-1.47(14) \\
-2.75(58)\end{array}$ & $\begin{array}{c}0.021^{*} \\
0.164 \\
0.008^{*}\end{array}$ \\
\hline
\end{tabular}

TFA = tibiofemoral angle, $\mathrm{DFA}=$ distal femoral angle, $\mathrm{PTA}=$ proximal tibial angle, $\mathrm{SD}=$ standard deviation, $\mathrm{CI}=$ confidence interval 


\section{Conclusions}

It has been observed in this study that northern Nigerian adults may have constitutional varus knee alignment compared to previous studies in other populations. This pre-existing varus alignment may be a risk factor for varus knee deformity in this population, although it will require further longitudinal studies to substantiate the finding. These findings should be taken into consideration during clinical examination, preoperative planning and postoperative evaluations of knee deformities in this population.

\section{References}

1. Zach L, Kuncicka L, Ruzicka P, Kocich R. Design, analysis and verification of a knee joint oncological prosthesis finite element model. Comput Biol Med 2014;54:53-60.

2. Moore KL, Dalley AF, Agur AMR. Clinically Oriented Anatomy. Wolters Kluwer Health; 2013.

3. Victor J. Rotational alignment of the distal femur: a literature review. Orthop Traumatol Surgery Res 2009;95:365-72.

4. Duggal N, Paci GM, Narain A, et al. A computer assessment of the effect of hindfoot alignment on mechanical axis deviation. Comput Methods Prog Biomed 2014;113:126-32.

5. Brouwer GM, van Tol AW, Bergink AP, et al. Association between valgus and varus alignment and the development and progression of radiographic osteoarthritis of the knee. Arthritis Rheum 2007;56:1204-11.

6. Sharma L, Song J, Dunlop D, et al. Varus and valgus alignment and incident and progressive knee osteoarthritis. Ann Rheum Dis 2010;69:1940-5.

7. Sharma L, Song J, Felson DT, et al. The role of knee alignment in disease progression and functional decline in knee osteoarthritis. JAMA 2001;286:188-95.

8. Sharma L, Chmiel JS, Almagor O, et al. The role of varus and valgus alignment in the initial development of knee cartilage damage by MRI: the MOST study. Ann Rheum Dis 2013;72:235-40.

9. Zhang Y, Xu L, Nevitt MC, et al. Comparison of the prevalence of knee osteoarthritis between the elderly Chinese population in Beijing and whites in the United States: The Beijing Osteoarthritis Study. Arthrit Rheum 2001;44:2065-71.

10. Braga L, Renner JB, Schwartz TA, et al. Differences in radiographic features of knee osteoarthritis in African-Americans and Caucasians: the Johnston county osteoarthritis project. Osteoarthritis Cartilage 2009;17:1554-61.

11. Wang Y, Zeng Y, Dai K, et al. Normal lower-extremity alignment parameters in healthy Southern Chinese adults as a guide in total knee arthroplasty. J Arthroplasty 2010;25:563-70.

12. Vaidya SV, Ranawat CS, Aroojis A, Laud NS. Anthropometric measurements to design total knee prostheses for the Indian population. J Arthroplasty 2000;15:79-85.

13. Tamari K, Tinley P, Briffa K, Aoyagi K. Ethnic-, gender-, and age-related differences in femorotibial angle, femoral antetorsion, and tibiofibular torsion: cross-sectional study among healthy Japanese and Australian Caucasians. Clin Anat 2006;19:59-67.
14. Tang W, Zhu Y, Chiu K. Axial Alignment of the Lower Extremity in Chinese Adults. J Bone Joint Surg Am 2000;82:1603.

15. Jabalameli M, Moghimi J, Yeganeh A, Nojomi M. Parameters of lower extremities alignment view in Iranian adult population. Acta Med Iran 2015;53:293-6.

16. Igbigbi PS, Msamati BC, Matanje B. Normal axial angles of the knee joint in adult indigenous Malawians. East Afr Med J 2003;80:415-8.

17. Kraus VB, Vail TP, Worrell T, McDaniel G. A comparative assessment of alignment angle of the knee by radiographic and physical examination methods. Arthrit Rheum 2005;52:17305.

18. Tetsworth K, Paley D. Malalignment and degenerative arthropathy. Orthop Clin N Am 1994;25:367-78.

19. Moreland JR, Bassett LW, Hanker GJ. Radiographic analysis of the axial alignment of the lower extremity. J Bone Joint Surg Am 1987;69:745-9.

20. Hsu RW, Himeno S, Coventry MB, Chao EY. Normal axial alignment of the lower extremity and load-bearing distribution at the knee. Clin Orthop Relat Res 1990;255:215-27.

21. Matsumoto T, Hashimura M, Takayama K, et al. A radiographic analysis of alignment of the lower extremities--initiation and progression of varus-type knee osteoarthritis. Osteoarthritis Cartilage 2015;23:217-23.

22. Song MH, Yoo SH, Kang SW, et al. Coronal alignment of the lower limb and the incidence of constitutional varus knee in korean females. Knee Surg Relat Res 2015;27:49-55.

23. Igbigbi PS, Msamati BC. Tibiofemoral angle in Malawians. Clin Anat 2002;15:293-6.

24. Igbigbi P, Kwatampora J. Lower limb angles of East African subjects. West Afr J Anat 1997;5:9-15.

25. El Fouhil AF, Khoshhal KI, Al-Nakshabandi NA, et al. Normal knee angles in the adult Saudi population. Saudi Med J 2011;32:1143-8.

26. Felson DT, Nevitt MC, Zhang Y, et al. High prevalence of lateral knee osteoarthritis in Beijing Chinese compared with Framingham Caucasian subjects. Arthrit Rheum 2002;46: 1217-22.

27. Ilahi OA, Kadakia NR, Huo MH. Inter-and intraobserver variability of radiographic measurements of knee alignment. Am J Knee Surg 2000;14:238-42.

28. Khattak MJ, Umer M, Davis ET, et al. Lower-limb alignment and posterior tibial slope in Pakistanis: a radiographic study. J Orthop Surg 2010;18.

29. Sabharwal S, Zhao C, Edgar M. Lower limb alignment in children: reference values based on a full-length standing radiograph. J Pediatr Orthop 2008;28:740-6.

30. Derek T, Cooke V, Scudamore RA, Greer W. Axial alignment of the lower limband its association with disorders of the knee. Oper Tech Sports Med 2000;8:98-107.

31. Cooke D, Scudamore A, Li J, et al. Axial lower-limb alignment: comparison of knee geometry in normal volunteers and osteoarthritis patients. Osteoarthrit Cartilage 1997;5:39-47.

32. Maini L, Singh S, Kushwaha NS, et al. Radiographic analysis of the axial alignment of the lower extremity in Indian adult males. J Arthroscopy Joint Surg 2015;2:128-31. 